\title{
Epididymitis caused by treatment with amiodarone
}

\author{
H H W IBSEN, * F FRANDSEN, $\dagger$ F BRANDRUP,* M MøLLER $\dagger$ \\ From the Departments of ${ }^{*}$ Dermatology and Venereology and $†$ Cardiology, Odense University Hospital, \\ Odense, Denmark
}

SUMMARY Epididymitis is described in a man aged 33 who had been treated with the antiarrhythmic agent, amiodarone. No signs of bacterial infection or anatomical abnormalities were found. Amiodarone as the cause of non-infectious epididymitis has been reported. This additional case stresses the importance of considering an adverse effect of amiodarone treatment as a cause when making a differential diagnosis of epididymitis.

Amiodarone is a benzofuran derivative, which has been used since the beginning of the 1980 s as a potent drug to treat patients with refractory cardiac arrhythmias. ${ }^{1}$ It has been associated with adverse reactions affecting the eyes, lung, skin, thyroid, and nervous system. ${ }^{1}$ We report a case of epididymitis associated with amiodarone treatment, which was observed in our clinic for venereal diseases.

\section{Case report}

A man aged 33 was referred to the venereology outpatient clinic in December 1988 because he had experienced swelling and pain in the scrotum for a few weeks. He had no history of venereal disease. In May 1987 he had suffered a myocardial infarction complicated by ventricular tachycardia and subsequent cardiac arrest. His recovery was complicated by intermittent refractory ventricular arrhythmias until treatment with amiodarone 600 to $800 \mathrm{mg}$ a day was instituted in August 1987. Additional treatment with aspirin 150 mg a day was given.

From November 1988 he gradually developed swelling and pain in the scrotum, but no dysuria. Examination showed an enlarged and tender left epididymis. One week later the enlargement became bilateral with varying hydrocele. His temperature was normal, no urethral discharge was seen, and microscopy of smears before and after prostatic massage showed no abnormality. Cultures of urethral swabs and urine failed to yield Neisseria gonorrhoeae or other pathogenic micro-organisms. Endourethral smears tested for Chlamydia trachomatis by a monoclonal antibody

Address for reprints: Dr H H W Ibsen, Department of Dermatology and Venereology, Odense University Hospital, 500 Odense C, Denmark

Accepted for publication 23 March 1989 based immunofluorescent test (Micro Trak) gave negative results. No tumour cells were seen in aspirated hydrocele liquid, and culture failed to yield Mycobacterium tuberculosis.

The patient was treated with erythromycin $2 \mathrm{~g}$ a day for 14 days, but without effect. As the pain and swelling worsened, he was admitted to hospital and treated with tetracycline hydrochloride $2 \mathrm{~g}$ for an additional 10 days and with various analgesics, including drugs of the morphine group. Despite treatment with antibiotics, his condition deteriorated. Treatment with amiodarone was stopped in favour of another antiarrhythmic agent. The swelling and pain subsided during the subsequent week. After six weeks only a slight painless persisting infiltration was found. When the treatment with amiodarone was discontinued the serum concentrations of amiodarone and its metabolite, desethyl amiodarone, ${ }^{2}$ were $2.8 \mathrm{mg} / 1$ and $2.2 \mathrm{mg} / \mathrm{l}$, respectively, and the concentrations in the hydrocele liquid were $1.1 \mathrm{mg} / 1$ and $0.9 \mathrm{mg} / 1$, respectively. A specimen of semen was not obtainable.

The patient's wife was also examined; no signs of gonorrhoea or chlamydial infection were found.

\section{Discussion}

Epididymitis in men under 35 is most often caused by $C$ trachomatis or $N$ gonorrhoeae. In men over 35 the usual infectious agents are coliform bacteria or Pseudomonas aeruginosa. Epididymitis occurs in rare cases of systemic tuberculosis and after the haematogenous spread of numerous other micro-organisms. ${ }^{3}$

Our patient showed no signs of infection or anatomical abnormalities and did not respond to prolonged treatment with antibiotics. As the pain and swelling subsided after amiodarone treatment was discontinued, amiodarone was the probable cause of the epididymitis. 
Amiodarone associated epididymitis has been described previously. ${ }^{125}$ Gasparich et al reviewed the records of 56 men treated with amiodarone for refractory ventricular tachycardia and found that six had histories of scrotal pain associated with epididymal enlargement. Only one of them responded to conventional antibiotic treatment, and he was the only patient with unilateral epididymitis. The mean amiodarone dose in the six patients with epididymitis was $700 \mathrm{mg}$ a day, and the duration of treatment before the onset of symptoms was 7-15 months. A significant association was found between the development of epididymitis and high dose amiodarone treatment for a long time. ${ }^{45}$ This accords with the findings in our patient, who had been treated with $600-800 \mathrm{mg}$ a day for 15 months.

Amiodarone accumulates in the testes and may cause a brown discolouration of semen. Adams et al measured the concentrations of amiodarone and its desethyl metabolite in necropsy samples from five patients who had received amiodarone treatment and found very high concentrations in the testes-among the highest concentrations noted in any tissue. ${ }^{6}$
Our findings point to the importance of considering this adverse effect of amiodarone treatment as an aetiological factor in epididymitis. If no bacterial or anatomical cause can be shown discontinuation of treatment or reduction of the dose should be considered in co-operation with the cardiologist.

\section{References}

1 Greene HL, Graham EL, Werner JA, et al. Toxic and therapeutic effects of amiodarone in the treatment of cardiac arrhythmias. $J$ Am Coll Cardiol 1983;2:1114-28.

2 Ward MJ, Routledge PA, Hutchings A, Morris JM. Association of seminal desethyl amiodarone concentration and epididymitis with amiodarone treatment. Br Med J 1988;296:19-20.

3 Berger RE. Epididymitis. In: Holmes KK, Mårdh P-A, Sparling PF, Wiesner PJ, eds. Sexually transmitted diseases. New York: McGraw-Hill, 1984:650-62.

4 Gasparich JP, Mason JT, Green HL, Berger RE, Krieger JN. Noninfectious epididymitis associated with amiodarone therapy. Lancet 1984;ii:1211-2.

5 Gasparich JP, Mason JT, Greene HL, Berger RE, Krieger JN. Amiodarone-associated epididymitis: drug-related epididymitis in the absence of infection. $J$ Urol 1985;133:971-2.

6 Adams PC, Holt P, Holt DW. Amiodarone in testis and semen. Lancet 1985; i:341. 